\title{
Central Cardiovascular Circuits Contribute to the Neurovascular Dysfunction in Angiotensin II Hypertension
}

\author{
Carmen Capone, ${ }^{1}$ Giuseppe Faraco, ${ }^{1}$ Jeffrey R. Peterson, ${ }^{2}$ Christal Coleman, ${ }^{1}$ Josef Anrather, ${ }^{1}$ Teresa A. Milner, ${ }^{1,4}$ \\ Virginia M. Pickel, ${ }^{1}$ Robin L. Davisson, ${ }^{2,3}$ and Costantino Iadecola ${ }^{1}$ \\ ${ }^{1}$ Department of Neurology and Neuroscience, Division of Neurobiology, and ${ }^{2}$ Department of Cell and Developmental Biology, Weill Cornell Medical College, \\ New York, New York 10021, 3'Department of Biomedical Sciences, College of Veterinary Medicine, Cornell University, Ithaca, New York 14850, and \\ ${ }^{4}$ Laboratory of Neuroendocrinology, The Rockefeller University, New York, New York 10065
}

Hypertension, a powerful risk factor for stroke and dementia, has damaging effects on the brain and its vessels. In particular, hypertension alters vital cerebrovascular control mechanisms linking neural activity to cerebral perfusion. In experimental models of slowdeveloping hypertension, free radical signaling in the subfornical organ (SFO), one of the forebrain circumventricular organs, is critical for the hormonal release and sympathetic activation driving the elevation in arterial pressure. However, the contribution of this central mechanism to the cerebrovascular alterations induced by hypertension remains uncertain. We tested the hypothesis that free radical production in the SFO is involved in the alterations in cerebrovascular regulation produced by hypertension. In a mouse model of gradual hypertension induced by chronic administration of subpressor doses of angiotensin II (AngII), suppression of free radicals in the SFO by overexpression of CuZn-superoxide dismutase (CuZnSOD) prevented the alteration in neurovascular coupling and endotheliumdependent responses in somatosensory cortex induced by hypertension. The SFO mediates the dysfunction via two signaling pathways. One involves SFO-dependent activation of the paraventricular hypothalamic nucleus, elevations in plasma vasopressin, upregulation of endothelin-1 in cerebral resistance arterioles and activation of endothelin type A receptors. The other pathway depends on activation of cerebrovascular AngII type 1 (AT1) receptors by AngII. Both pathways mediate vasomotor dysfunction by inducing vascular oxidative stress. The findings implicate for the first time the SFO and its efferent hypothalamic pathways in the cerebrovascular alterations induced by AngII, and identify vasopressin and endothelin- 1 as potential therapeutic targets to counteract the devastating effects of hypertension on the brain.

\section{Introduction}

Cerebral blood vessels are the premier target of the brain damage produced by hypertension, a major risk factor for stroke and dementia (Iadecola and Davisson, 2008; Unverzagt et al., 2011). Chronic hypertension is well known to alter cerebrovascular structure and function (Cipolla, 2007). In particular, hypertension disrupts vital neurovascular mechanisms coupling the local delivery of blood flow with the energetic needs of active brain regions (Kazama et al., 2004; Jennings et al., 2005; Iadecola and Davisson, 2008). The resulting mismatch between blood supply and energy demands is particularly damaging to subcortical white matter regions perfused by poorly collateralized arteriolar networks at the interface between adjacent vascular territories (Markus et al., 2000; Fernando et al., 2006; Iadecola, 2010). Thus, subcortical white matter lesions are closely related to hypertension and are associated with an increased risk of stroke, vascular

Received Dec. 16, 2011; revised Jan. 25, 2012; accepted Feb. 17, 2012.

Author contributions: C.C., G.F., J.A., R.L.D., and C.I. designed research; C.C., G.F., J.R.P., C.G.C., J.A., and T.A.M. performed research; C.C., G.F., J.R.P., T.A.M., R.L.D., and C.I. analyzed data; C.C., T.A.M., V.M.P., R.L.D., and C.I. wrote the paper.

This work was supported by NIH Grants HL96571 and HL98351.

Correspondence should be addressed to Dr. Costantino ladecola, Division of Neurobiology, 407 East $61^{\text {st }}$ Street; Room 303, New York, NY 10065. E-mail: coi2001@med.cornell.edu.

DOI:10.1523/JNEUROSCI.6262-11.2012

Copyright $\odot 2012$ the authors $\quad 0270-6474 / 12 / 324878-09 \$ 15.00 / 0$ cognitive impairment and Alzheimer's disease (Englund et al., 1988; Matsushita et al., 1994; Vermeer et al., 2003; van Dijk et al., 2004).

The mechanisms by which high arterial pressure (AP) disrupts the cerebral blood supply remain to be defined. Mounting evidence suggests that the subfornical organ (SFO), one of the forebrain circumventricular organs, plays a critical role in the hormonal and neural changes responsible for the hypertension induced by angiotensin II (AngII), a peptide involved in human hypertension (Peterson et al., 2006; Osborn et al., 2007; Harrison and Gongora, 2009). Administration of small doses of AngII not sufficient to immediately increase AP can induce a gradual hypertension if the administration is protracted for several days ("slow-pressor hypertension") (Dickinson and Lawrence, 1963; Kawada et al., 2002). Evidence suggests that AngII, a peptide that does not cross the blood-brain barrier (BBB), acts on the SFO, which lacks a $\mathrm{BBB}$, to induce local formation of reactive oxygen species (ROS) via activation of local AngII type 1 (AT1) receptors (Peterson et al., 2006). The resulting changes in calcium homeostasis (Zimmerman et al., 2005) are thought to activate neural pathways projecting from the SFO to the paraventricular hypothalamic nucleus (PVN), which, in turn, mediates the hypertension by releasing pressor hormones and activating excitatory input to brainstem and spinal nuclei controlling sympathetic outflow (Anderson et al., 2001; McKinley et al., 2003). However, 
A
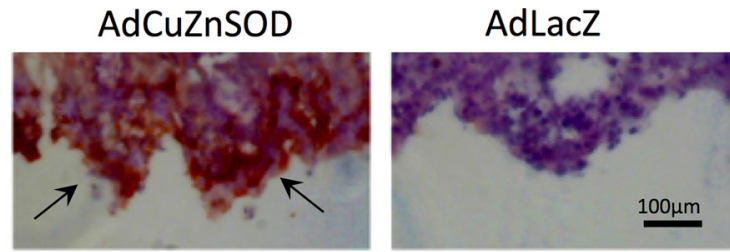

Whisker

Barrel Cortex
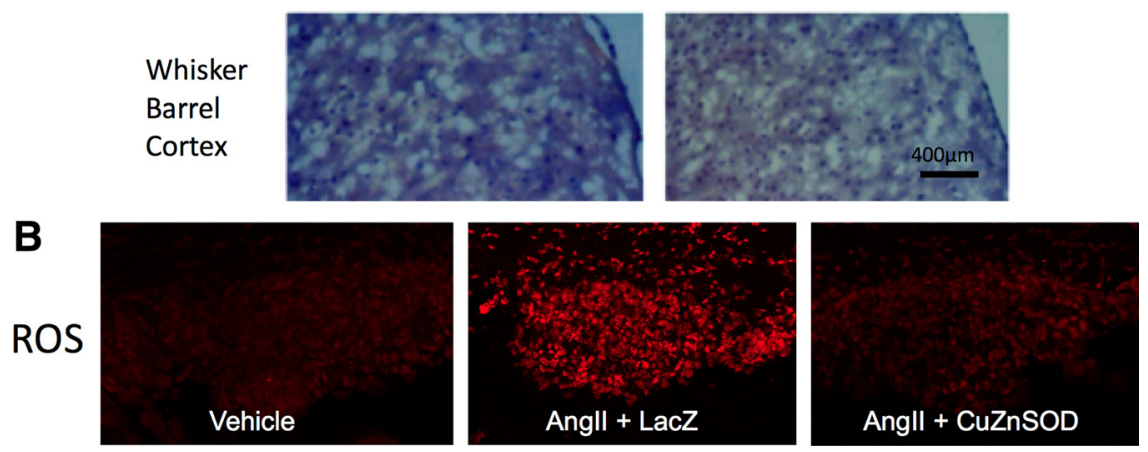

Figure 1. Adenoviral gene transfer of CuZnSOD increases SOD immunoreactivity in the SFO, but not in the whisker barrel cortex $(\boldsymbol{A})$, and suppresses ROS production in the SFO (B).

it remains unclear whether the SFO and related central networks also play a role in the cerebrovascular alterations induced by slow-pressor hypertension.

In this study, we tested the hypothesis that central pathways involving the SFO participate in the vasomotor dysfunction induced by slow-pressor AngII infusion (Capone et al., 2010, 2011). Using adenoviral gene transfer of the ROS scavenging enzyme CuZn-superoxide dismutase (CuZnSOD), we found that such cerebrovascular dysfunction requires production of ROS in the SFO. At variance with acute AngII hypertension, the cerebrovascular alterations induced by slow-pressor hypertension are mediated by two distinct mechanisms. One mechanism involves vasopressin (AVP) release, upregulation of endothelin-1 (ET1) in cerebral arterioles and activation of $\mathrm{ET} 1$ type $\mathrm{A}\left(\mathrm{ET}_{\mathrm{A}}\right)$ receptors, and the other activation of AT1 receptors by AngII. Both ET1 and AngII exert their deleterious vascular effects through a common pathway involving vascular oxidative stress. These findings provide evidence for a previously unrecognized contribution of cardiovascular regulatory nuclei in the neurovascular dysfunction of hypertension and implicate AVP and ET1 in its mechanisms.

\section{Materials and Methods}

Methods for surgical preparation of mice, blood pressure measurement, neocortical application of drugs, and monitoring cerebral blood flow (CBF) using laser-Doppler flowmetry (LDF) have been described in detail in previous publications (Iadecola et al., 1999; Kazama et al., 2004; Girouard et al., 2007; Park et al., 2008; Capone et al., 2009) and are briefly summarized. Studies were conducted in C57BL/6J male mice (age, 2-3 months; body weight, 20-30 g), obtained from Jackson Laboratories. All procedures were approved by the Institutional Animal Care and Use Committee of Weill Cornell Medical College.

\section{Osmotic minipumps implantation}

Osmotic minipumps containing vehicle (saline) or AngII (600 $\left.\mathrm{ng} \cdot \mathrm{kg}^{-1} \cdot \mathrm{min}^{-1}\right)$ were implanted subcutaneously in mice $(n=5$ per group) under isoflurane anesthesia. Systolic blood pressure was monitored daily in awake mice using tail-cuff plethysmography, as previously described (Kazama et al., 2004; Capone et al., 2010, 2011). In some experiments the AVP V1a receptor antagonist SR49059 $(4 \mathrm{mg} / 100 \mathrm{ml})$ (Thibonnier et al., 2002) was administered via the drinking water 7-14 d after pump implantation.

\section{Adenoviral gene transfer}

Mice underwent SFO-targeted stereotaxic microinjection of an adenovirus encoding CuZnSOD (AdCuZnSOD) or control LacZ (AdLacZ) as described previously (Zimmerman et al., 2004; Peterson et al., 2009). To avoid damage to the neocortex in which CBF was recorded, the micropipette for viral vector delivery was inserted in the hemisphere contralateral to the site of CBF measurement. With this method, viral transduction is largely restricted to the SFO and does not involve other brainstem cardiovascular nuclei (Peterson et al., 2009). In the present study, the efficiency and regional selectivity of the viral transduction of the SFO was verified postmortem by SOD immunocytochemistry (Fig. 1). One week after gene transfer mice were implanted with minipumps delivering slow-pressor doses of AngII or vehicle as described above, and mice were instrumented for $\mathrm{CBF}$ recording at day 14. Separate mice were instrumented for assessment of cerebrovascular reactivity before and 30 min after acute intravenous administration of pressor doses of AngII ( $7.5 \mathrm{ng} / \mathrm{min}$ per mouse, i.v.) as previously described (Kazama et al., 2003, 2004).

General surgical procedures for $C B F$ studies

Mice were anesthetized with isoflurane in a mixture of $\mathrm{N}_{2}$ and $\mathrm{O}_{2}$ (Induction, 5\%; Maintenance, 2\%). The trachea was intubated and mice were artificially ventilated with an oxygen-nitrogen mixture. The $\mathrm{O}_{2}$ concentration in the mixture was adjusted to provide an arterial $\mathrm{pO}_{2}\left(\mathrm{P}_{\mathrm{a}} \mathrm{O}_{2}\right)$ of 120-130 mmHg (Capone et al., 2009, 2010, 2011). One of the femoral arteries was cannulated for recording mean AP (MAP) and collecting blood samples. Rectal temperature was maintained at $37^{\circ} \mathrm{C}$ using a thermostatically controlled rectal probe connected to a heating pad. Endtidal $\mathrm{CO}_{2}$, monitored by a $\mathrm{CO}_{2}$ analyzer (Capstar-100, CWE Inc.), was maintained at $2.6-2.7 \%$ to provide a $\mathrm{pCO}_{2}$ of $33-36 \mathrm{mmHg}$ (Capone et al., 2009, 2010). After surgery, isoflurane was discontinued and anesthesia was maintained with urethane $(750 \mathrm{mg} / \mathrm{kg}$, i.p.) and chloralose $(50$ $\mathrm{mg} / \mathrm{kg}$, i.p.). Throughout the experiment the level of anesthesia was monitored by testing corneal reflexes and motor responses to tail pinch.

\section{Monitoring cerebral blood flow}

A small craniotomy $(2 \times 2 \mathrm{~mm})$ was performed to expose the parietal cortex, the dura was removed, and the site was superfused with Ringer's solution $\left(37^{\circ} \mathrm{C}\right.$; $\mathrm{pH} 7.3-7.4$; composition in mм: $137 \mathrm{NaCl}, 5 \mathrm{KCl}, 1$ $\mathrm{MgCl}_{2}, 1.95 \mathrm{Na}_{2} \mathrm{HPO}_{3}, 15 \mathrm{NaHCO}_{3}, 2 \mathrm{CaCl}_{2}$ ). CBF was continuously monitored at the site of superfusion with a laser-Doppler probe (Perimed) positioned stereotaxically on the cortical surface. The outputs of the flowmeter and blood pressure transducer were connected to a data acquisition system (PowerLab) and saved on a computer for off-line analysis. $\mathrm{CBF}$ values were expressed as percentage increases relative to the resting level. Zero values for CBF were obtained after the heart was stopped by an overdose of isoflurane at the end of the experiment. Although LDF is not quantitative, it monitors relative changes in CBF quite accurately (for review, see Iadecola, 1997).

\section{ROS detection}

ROS production in the somatosensory cortex was assessed by hydroethidine (DHE) microfluorography as previously described (Girouard et al., 2006, 2007; Capone et al., 2010, 2011). DHE (2 $\mu \mathrm{M}$; Invitrogen) was superfused on the somatosensory cortex for a total of $60 \mathrm{~min}$. The brain was removed, frozen, and coronal sections (thickness, $20 \mu \mathrm{m}$ ) were cut through cortex underlying the cranial window using a cryostat. Sections were analyzed using a Nikon Eclipse E800 fluorescence microscope equipped with a custom filter set for detection of DHE oxidation products (Girouard et al., 2006, 2007; Capone et al., 2010, 2011). Images were acquired with a digital camera (Coolsnap, Roper Scientific) and analyzed in a blinded manner using the IPLab software (Scanalytics), as described 
previously (Capone et al., 2011). Fluorescent intensities of all sections (20 per animal) were added, divided by the total number of pixels analyzed, and expressed as relative fluorescence units. Methods for assessing ROS production in the SFO using DHE have been published (Zimmerman et al., 2004). After $14 \mathrm{~d}$ of AngII infusion, brains were removed, frozen, and sectioned in a cryostat (thickness, $30 \mu \mathrm{m}$ ). Brain sections including the SFO were incubated for $5 \mathrm{~min}$ with DHE $(1 \mu \mathrm{M})$. After washing with PBS, DHE fluorescence was visualized by confocal microscopy (Zeiss LSM 510).

Immunocytochemistry at the light and electron microscopy levels For light and confocal microscopy, mice ( $n=4$ per group) were perfused transcardially with PBS followed by $4 \%$ paraformaldehyde in PBS. Brains were removed, stored overnight in the same fixative at $4^{\circ} \mathrm{C}$, and then submerged in 30\% sucrose solution for at least $2 \mathrm{~d}$. Coronal brain sections (thickness, $20 \mu \mathrm{m}$ ) were cut through the somatosensory cortex and the PVN using a cryostat. After antigen retrieval with proteinase K, sections were permeabilized in PBS with $0.5 \%$ Triton X-100 (Sigma) and then blocked in PBS with $0.1 \%$ Triton X-100 (Sigma) and 5\% of normal donkey or goat serum. Sections were incubated with primary antibodies (ET1: 1:200, rabbit polyclonal antibody, Peninsula Laboratories; AVP: $1: 16,000$, guinea pig, Peninsula Laboratories; Millipore Bioscience Research Reagents; CD31: 1:200, rat monoclonal antibody, BD Biosciences) at $4^{\circ} \mathrm{C}$ overnight. The specificity of the immunolabel was tested previously (Tharaux et al., 1999) and was verified by omitting the primary antibody. After rinsing, sections were incubated with secondary antibodies. AVP immunolabeling was revealed by a biotinylated goat anti guinea pig IgG (1:400; Inc Star) whereas ET-1 and CD31 immunolabeling were revealed by donkey FITC and Cy5-conjugated antibodies (1:200; Jackson ImmunoResearch Laboratories), respectively. A Nikon light microscope or a Leica confocal microscope were used to visualize the signal associated with each antibody (Capone et al., 2010). For immunoelectron microscopy, mice were perfusion fixed with heparin-saline followed by 3.75\% acrolein and 2\% paraformaldehyde in PBS (Milner et al., 2010). Coronal sections ( $40 \mu \mathrm{m}$ thick) were cut through the somatosensory cortex on a Vibratome and processed for ET1 immunoreactivity using the immunogold-silver method (Chan et al., 1990). Briefly, sections were incubated in anti-ET1 (1:1000; Peninsula) in $0.1 \%$ bovine serum albumin, $0.1 \mathrm{M}$ Tris saline, $\mathrm{pH} 7.4$, for $1 \mathrm{~d}$ at room temperature. Sections then were rinsed, incubated $2 \mathrm{~h}$ in goat anti-rabbit IgG conjugated to $1 \mathrm{~nm}$ gold particles (AuroProbe One; GE Healthcare Life Sciences), rinsed in $\mathrm{PB}$-saline, postfixed in glutaraldehyde and rinsed again. Gold particles were intensified by incubation for 6 min with silver solution (GE Healthcare Life Sciences). Sections then were cut $(70 \mathrm{~nm}$ thick) on a Leica ultratome, collected on copper grids, counter-stained and imaged on a Tecnai transmission electron microscope.

\section{ELISA and RT-PCR}

ET1 was measured in cerebrovascular preparations using commercially available ELISA kit (Enzo Life Sciences). Cerebral blood vessels isolated from the brain surface by stripping the pia under a surgical microscope. This preparation includes large, medium size and small cerebral blood vessels (Park et al., 2011). Vessel homogenates were prepared in $1 \mathrm{M}$ acetic acid containing $15 \mu \mathrm{M}$ Pepstatin A (Calbiochem) and purified over C18 columns as suggested by the manufacturer. Plasma AVP was measured using a competitive EIA kit (Cayman Chemicals) after purification over a phenyl matrix (Bond elut-PH, Varian). qRT-PCR was used to measure mRNA for endothelin converting enzyme-1 (ECE1), a protease that cleaves the ET precursor (big ET) into ET. Primers were 5' -GCCTACCG GGCGTACCAGAAC-3' and 5'-GGTGTGCGGACAGAGCACCAG-3'. RNA was prepared and qRT-PCR was performed as previously described (Kunz et al., 2008). ECE1 mRNA levels were normalized to hypoxanthine phosphoribosyltransferase mRNA and relative expression levels were calculated as described previously (Kunz et al., 2008).

\section{Experimental protocols}

CBF responses to whisker stimulation, endothelium-dependent vasodilators or adenosine. After stabilization of MAP and blood gases, the whiskerbarrel region of the somatosensory cortex was activated for $60 \mathrm{~s}$ by stroking the contralateral facial whiskers (Capone et al., 2009, 2010) and the
A

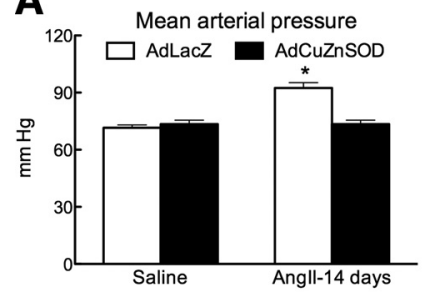

B
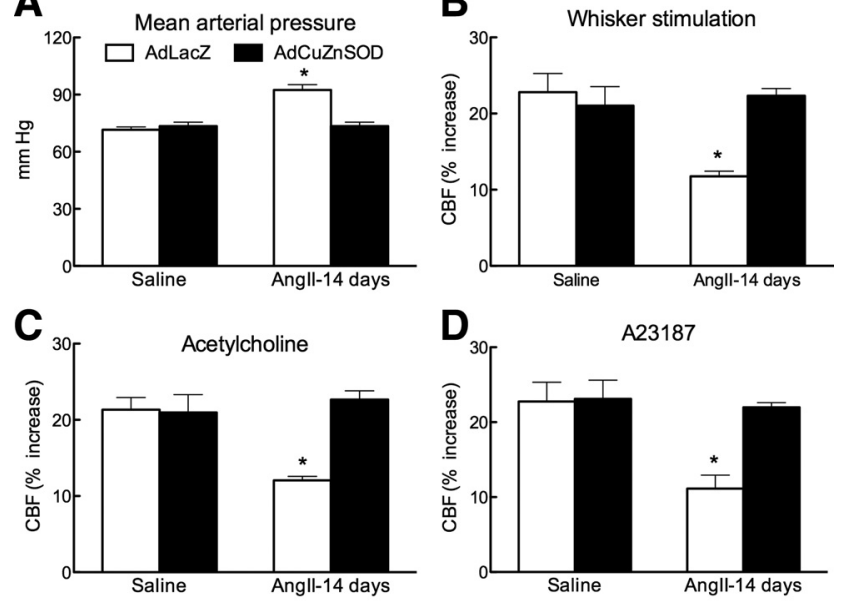

$\mathbf{E}$

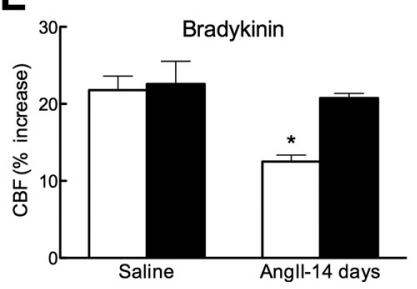

$\mathbf{F}$

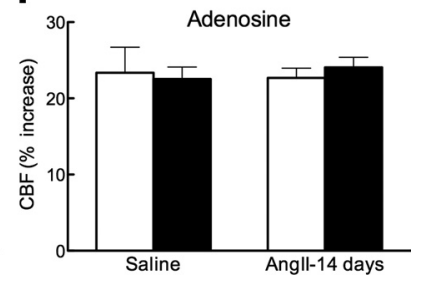

Figure 2. A, CuZnSOD viral gene transfer to the SF0, but not gene transfer of the control virus expressing LacZ, blocks the increase in arterial pressure in mice receiving slow-pressor doses of Angll $\left(600 \mathrm{ng} \cdot \mathrm{kg}^{-1} \cdot \min ^{-1}\right) \cdot \boldsymbol{B}-\boldsymbol{E}$, CuZnSOD viral gene transfer prevents the attenuation of the $(B F$ response to whisker stimulation $(\boldsymbol{B})$, and to endothelium-dependent vasodilators $(\boldsymbol{C}-\boldsymbol{E})$. $\boldsymbol{F}$, Angll does not alter the CBF response to adenosine, with or without CuZnSOD viral gene transfer, attesting to the reactivity of the preparation $\left({ }^{*} p<0.05\right.$ from respective saline group; ANOVA and Tukey's test; $n=6$ per group).

A

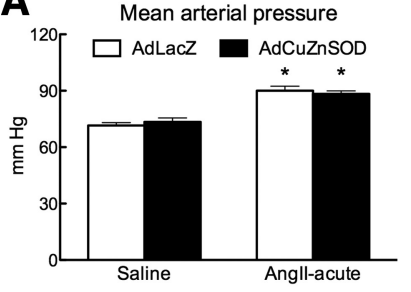

C

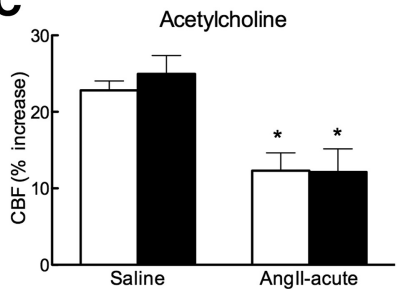

B Whisker stimulation

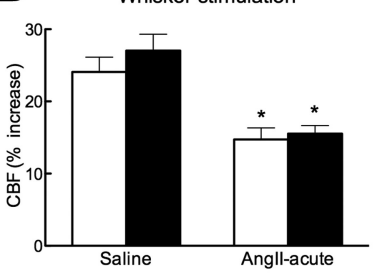

D

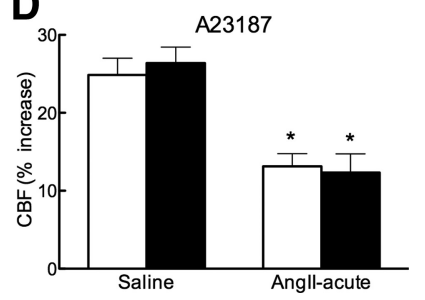

Figure 3. Acute administration of pressor doses of Angll ( $7.5 \mathrm{ng} / \mathrm{min}$ per mouse, i.v.) induces hypertension $(\boldsymbol{A})$ and cerebrovascular dysfunction $(\boldsymbol{B}-\boldsymbol{D})$, effects not prevented by CuZnSOD viral gene transfer to the SFO $\left({ }^{*} p<0.05\right.$ from saline; $n=5$ per group).

evoked changes in $\mathrm{CBF}$ were recorded. $\mathrm{CBF}$ responses to acetylcholine (ACh; $10 \mu \mathrm{M})$, bradykinin $(50 \mu \mathrm{M})$, the $\mathrm{Ca}^{2+}$ ionophore $\mathrm{A} 23187(3 \mu \mathrm{M})$ and adenosine $(400 \mu \mathrm{M})$ (Capone et al., 2009, 2010). In most cases, all $\mathrm{CBF}$ responses were tested in each mouse and evoked in a random sequence. All agents were dissolved in a modified Ringer's solution. These agents were selected because they produce vasodilation through different mechanisms. $\mathrm{ACh}$ induces $\mathrm{CBF}$ increases mediated by endothelial nitric oxide and muscarinic receptors (Yamada et al., 2001), while bradykinin and A23187 act via endothelial cyclooxygenase-1 products via receptor-dependent and 
A
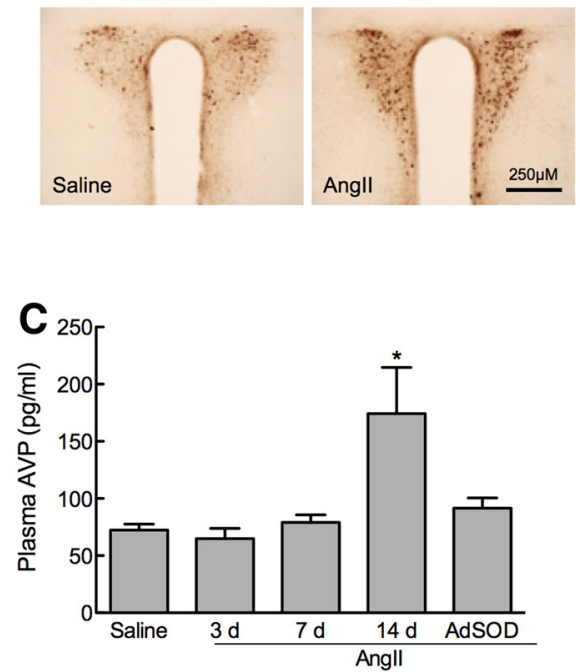

Whisker stimulation
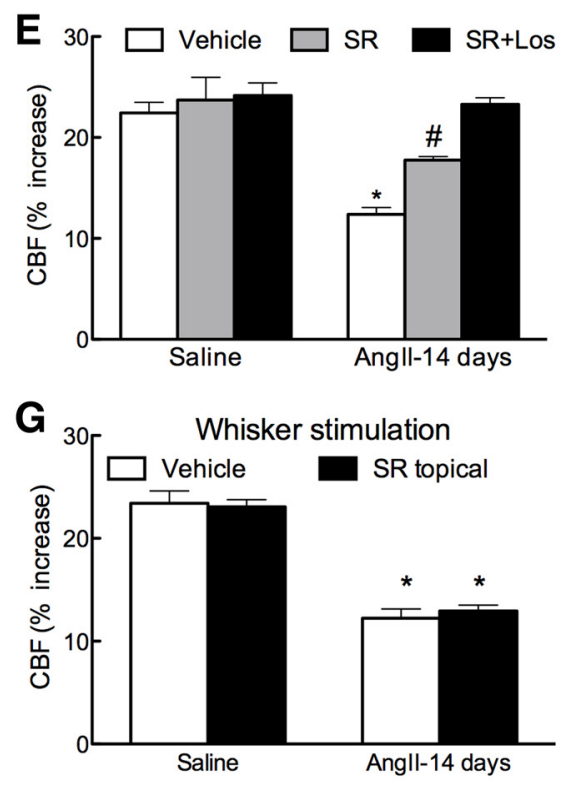
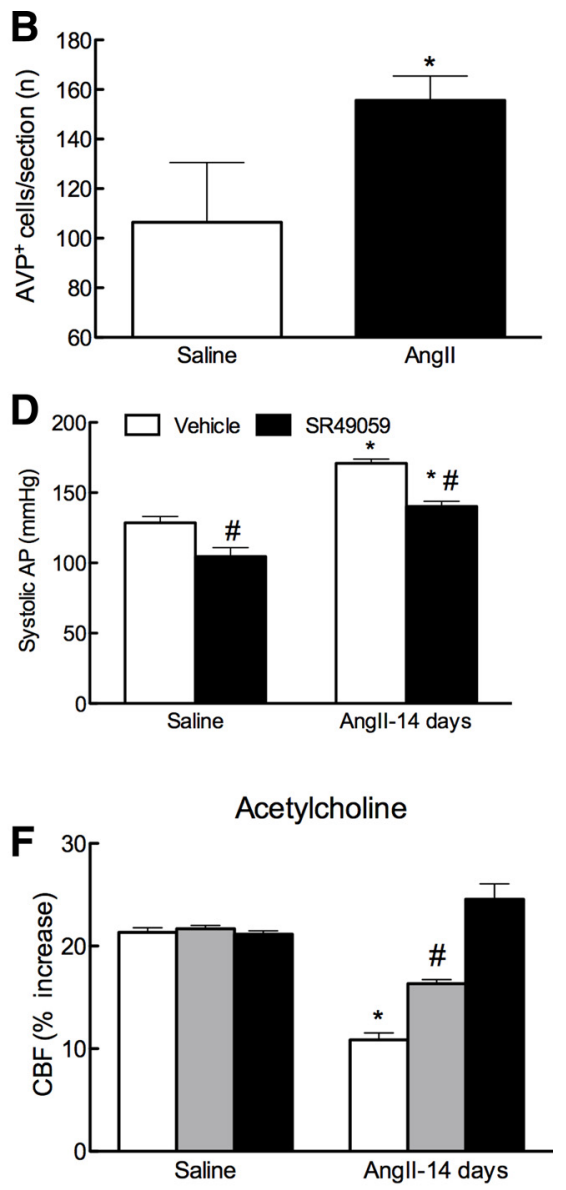

H

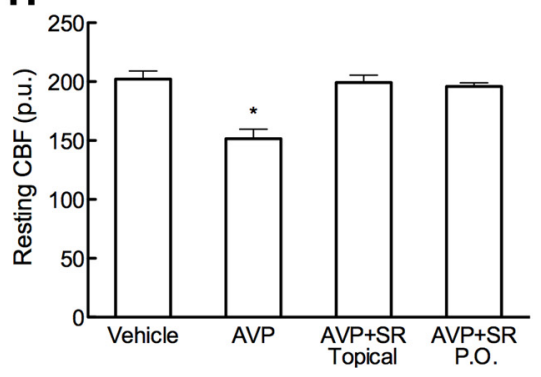

Figure 4. $A-C$, Slow-pressor Angll hypertension enhances AVP immunoreactivity $(A)$ and increases the number of AVP-positive cells in the PVN at $14 \mathrm{~d}\left({ }^{*} p<0.05\right.$ from saline; $n=5$ per group) (B). Plasma AVP is also elevated at $14 \mathrm{~d}(\boldsymbol{C})$ $\left({ }^{*} p<0.05\right.$ from saline; $n=5$ per group). $C$, Adenoviral gene transfer of CUZnSOD (AdSOD) in SFO prevents the plasma AVP increase. $\boldsymbol{D}-\boldsymbol{F}$, Administration of the V1a AVP receptor antagonist SR49059 $(4 \mathrm{mg} / 100 \mathrm{ml}$ in drinking water, days 7-14 of Angll infusion) attenuates resting systolic AP, but does not prevent the AP rise induced by Angll. $\boldsymbol{D}$, Systolic AP was measured by tail cuff plethysmography ( ${ }^{*} p<0.05$ form respective saline group; $\# p<005$ from vehicle; $n=6$ per group). $\boldsymbol{E}, \boldsymbol{F}$, SR49059 (SR) partially prevents the attenuation in the response to whisker stimulation $(\boldsymbol{E})$ or topical application of acetylcholine $(\boldsymbol{F})$ induced by Angll. SR49059 + losartan (Los; $5 \mu \mathrm{m})$ completely prevents the attenuation $(\boldsymbol{E}, \boldsymbol{F})\left({ }^{*} p<0.05\right.$ from respective saline group; ${ }^{\#} p<0.05$ from vehicle, $S R+$ Los, and respective saline group; $n=6$ per group). $\mathbf{G}$, Application of SR49059 $(10 \mu \mathrm{M})$ to the cranial window does not block the attenuation of functional hyperemia induced by chronic Angll ( ${ }^{*} p<0.05$ from saline; $n=5$ per group). $\boldsymbol{H}$, The reduction in resting (BF produced by neocortical application of AVP is blocked by SR49059, either applied to the neocortex $(10 \mu \mathrm{M})$ or administered in the drinking water for days 7-14 of Angll infusion (P.0.) ( ${ }^{*} p<0.05$ from vehicle; $n=5$ per group).

-independent mechanisms, respectively (Niwa et al., 2001). Adenosine is a smooth muscle relaxant whose action is independent of the endothelium (Phillis, 1989). Agents were applied at concentrations previously determined not to be supramaximal (Iadecola et al., 1999). In some experiments response were examined with vehicle superfusion and $30 \mathrm{~min}$ after superfusion with SR49059 (10 $\mu \mathrm{M})$, BQ123 (1 $\mu \mathrm{M})$ (Cardillo et al., 2002) or losartan (5 $\mu \mathrm{M})$ (Kazama et al., 2004).
ROS measurement. The protocol for these experiments was identical to that of the CBF studies. After stabilization of MAP and blood gases DHE was superfused on the cranial window for $60 \mathrm{~min}$ and then the brain was removed and processed for determination of ROS as described above.

\section{Data analysis}

Data in text and figures are expressed as means \pm SE. Two-group comparisons were analyzed by the two-tailed Student's $t$ test. Multiple comparisons were evaluated by the ANOVA and Tukey's test. Probability values of $<0.05$ were considered statistically significant.

\section{Results}

$\mathrm{CuZnSOD}$ adenoviral gene transfer to the SFO prevents the neurovascular dysfunction induced by slow-pressor AngII hypertension

ROS production in the SFO has emerged as a crucial factor in the cardiovascular changes induced by slow-pressor AngII administration (Peterson et al., 2006). Therefore, we investigated whether ROS signaling in the SFO contributes to the vasomotor dysfunction observed in this model of hypertension. Adenoviral gene transfer of the ROS scavenging enzyme CuZnSOD (AdCuZnSOD) was used to suppress ROS production in the SFO, whereas gene transfer of LacZ (AdLacZ) served as control (Lindley et al., 2004; Zimmerman et al., 2004) (Fig. 1). In mice treated with control vector (AdLacZ), AngII increased AP (Fig. 2A) and attenuated the increase in $\mathrm{CBF}$ induced by whisker stimulation (Fig. $2 B$ ) and by neocortical application of the endothelium-dependent vasodilators ACh, A23187 or bradykinin (Fig. $2 C-E$ ), as previously reported (Capone et al., 2011). The increase in CBF produced by application of the smooth muscle relaxant adenosine was not affected (Fig. $2 F$ ), suggesting that the attenuation of functional hyperemia and endotheliumdependent responses was not secondary to a nonspecific vasoparalysis. CuZnSOD gene transfer increased CuZnSOD immunoreactivity in the SFO, but not in the somatosensory cortex (Fig. 1A), and, consistent with previous studies (Zimmerman et al., 2004), attenuated the ROS increase produced by AngII infusion in SFO at $14 \mathrm{~d}$ (Fig. $1 \mathrm{~B}$ ). Importantly, AdCuZnSOD in SFO prevented the increase in $\mathrm{AP}$ and the cerebrovascular dysfunction induced by AngII infusion (Fig. 2), but did not affect the hypertension and cerebrovascular alterations induced by acute administration of pressor doses of AngII (Fig. 3). Thus, suppression of ROS production in the SFO attenuates the vasomotor dysfunction induced by slow-pressor AngII hypertension, but not that induced by acute AngII hypertension. 
Table 1. Effect of the receptor antagonists used on resting cerebral blood flow

\begin{tabular}{|c|c|c|c|}
\hline \multirow[b]{2}{*}{ Drug } & \multicolumn{2}{|c|}{ CBF (perfusion units) } & \multirow[b]{2}{*}{$n$} \\
\hline & Before & After & \\
\hline Losartan $^{a}$ & $26 \pm 4$ & $25 \pm 5$ & 5 \\
\hline $\mathrm{BQ} 123^{a}$ & $22 \pm 3$ & $25 \pm 4$ & 5 \\
\hline SR49059 ${ }^{a}$ & $22 \pm 4$ & $21 \pm 3$ & 5 \\
\hline $\mathrm{BQ} 123^{a}+$ Losartan $^{a}$ & $22 \pm 2$ & $21 \pm 2$ & 5 \\
\hline SR $49059^{b}+$ Losartan $^{a}$ & $23 \pm 3$ & $22 \pm 4$ & 6 \\
\hline $\mathrm{BQ} 123^{a}+\mathrm{SR} 49059^{b}$ & $24 \pm 2$ & $23 \pm 3$ & 5 \\
\hline
\end{tabular}

${ }^{a}$ Neocortical application.

${ }^{b}$ In drinking water during days 7-14 of the Angll infusion.

$p>0.05 ; t$ test.

\section{Slow-pressor AngII increases plasma AVP, which contributes} the vasomotor dysfunction

The observation that the cerebrovascular effects of AngII depend on ROS production in the SFO raises the possibility that neurohumoral mechanisms involving in the SFO play a role. The PVN is the target of a major efferent pathway from the SFO and AngII is well known to release AVP through activation of this pathway (Ferguson and Kasting, 1986; Anderson et al., 2001). Therefore, we examined whether slow-pressor AngII leads to AVP release, and, if so, whether AVP participates in the cerebrovascular dysfunction. AngII infusion increased AVP immunoreactivity in the PVN (Fig. $4 A, B$ ) and elevated plasma levels of AVP at $14 \mathrm{~d}$, but not at 3 or $7 \mathrm{~d}$ (Fig. 4 C). The increase in plasma AVP was abolished by SFO viral gene transfer of CuZnSOD (Fig. 4C). The AVP V1a receptor antagonist SR49059, administered orally during day 7-14 of vehicle or AngII infusion, reduced baseline AP in mice receiving vehicle (saline), but did not block the elevation in AP induced by AngII (Fig. 4D). However, SR49059, at a dose effective in completely blocking the effects of AVP on CBF (Fig. 4H), prevented the cerebrovascular dysfunction induced by AngII only partially (Fig. $4 E, F$ ). Next, we examined the possibility that plasma AVP alters cerebrovascular regulation acting directly on V1a receptors in cerebral blood vessels (Faraci et al., 1994; Fernández et al., 2001). Application of SR49059 to the cranial window, at a concentration $(10 \mu \mathrm{M})$ effective in preventing the cerebrovascular effects of AVP (Fig. $4 H$ ), did not attenuate resting CBF (Table 1) or the neurovascular dysfunction induced by AngII (Fig. 4G). Thus, V1a receptors are not the final mediator of the CBF dysfunction, but they are required for the cerebrovascular effects of slow-pressor AngII hypertension.

ET1 increases in cerebral blood vessels and contributes to the cerebrovascular dysfunction induced by AngII

AVP upregulates the potent vasoactive peptide ET1 in systemic vessels ( $\mathrm{Li}$ et al., 2003a). Therefore, we investigated whether AVP might contribute to the cerebrovascular effects of chronic AngII by increasing ET1 in cerebral blood vessels. AngII infusion induced a profound increase in ET in pial vessel preparations, assessed by ELISA (Fig. 5A). The ET elevation was observed between 7 and $14 \mathrm{~d}$ of AngII infusion, and was suppressed by oral treatment with the V1a receptor antagonist SR49059 (Fig. 5A). AngII infusion increased mRNA expression of endothelin converting enzyme-1 (ECE-1) in pial vessel preparations between 7 and $14 \mathrm{~d}$ (Fig. 5B), suggesting local vascular conversion of the inactive precursor peptide (big ET1) into ET1. In support of this hypothesis, cofocal microscopy showed an abundance of ET1 immunoreactivity in pial arterioles of the somatosensory cortex of mice infused with AngII (Fig. 5C). Similarly, electron microscopy demonstrated an increase in ET1 immunoreactivity in cerebral microvascular endothelial cells of AngII-infused mice (Fig.
5D). To determine whether ET1 contributes to the cerebrovascular alterations induced by AngII the $\mathrm{ET}_{\mathrm{A}}$ receptor antagonist BQ123 was superfused in the cranial window at a concentration $(1 \mu \mathrm{M})$ sufficient to block the vascular effects of ET1 (data not shown). BQ123 did not affect the AP elevation (Saline, $74 \pm 2$; AngII, $91 \pm 5 \mathrm{mmHg} ; p<0.05$ ) or resting CBF (Table 1), but it partially rescued the cerebrovascular dysfunction (Fig. 6A,B). These observations, collectively, raise the possibility that AVP induces ET1 expression in cerebral blood vessels, which, in turn, mediates the alteration in cerebrovascular regulation. If so, the rescuing effects of BQ123 and SR49059 on the cerebrovascular dysfunction should not be additive. Consistent with this prediction, topical application of BQ123 in mice treated with SR49059 (oral administration, days 7-14 of AngII infusion) did not enhance the protection (Fig. $6 A, B$ ), indicating that $\mathrm{V} 1 \mathrm{a}$ and $\mathrm{ET}_{\mathrm{A}}$ receptors do not act via distinct mechanisms resulting in additive effects.

\section{AT1 receptors mediate the AVP-ET1-independent component of the cerebrovascular dysfunction}

The findings presented above indicate that AVP and ET1 can account for only part of the alterations in neurovascular regulation induced by AngII. Therefore, we tested whether AngII mediates the remainder of the cerebrovascular dysfunction by activating AT1 receptors in cerebral blood vessels. To this end, we examined the effect of topical application of the AT1 receptor antagonist losartan in mice treated with slow-pressor AngII. Losartan partially reversed the cerebrovascular effects of AngII (Fig. $6 C, D$ ), without altering the AP increase (Saline, $75 \pm 2$; AngII, $92 \pm 6 \mathrm{mmHg} ; p<0.05$ ) or resting CBF (Table 1). In contrast, losartan completely counteracted the cerebrovascular dysfunction induced by acute administration of pressor doses of AngII (Fig. 6E,F), attesting to its ability to fully inhibit AT1 receptors. Next, we investigated whether the component of the cerebrovascular dysfunction mediated by AVP and ET1 is distinct from that mediated by AngII. If so, the rescue of the dysfunction afforded by losartan should be additive with that conferred by SR49059 or BQ123. As anticipated, topical application of losartan in mice treated orally with SR49059 completely rescued the dysfunction (Fig. 4E,F). Similarly, coapplication of BQ123 plus losartan rescued the dysfunction in full (Fig. 6G,H). Thus, AVP and ET1 exert their effect through pathways distinct from those of AngII.

\section{ET1 and AT1 receptors mediate the cerebrovascular dysfunction through ROS}

The cerebrovascular dysfunction induced by slow-pressor doses of AngII is mediated by vascular oxidative stress mediated by the ROS-producing enzyme NADPH oxidase (Capone et al., 2011). Considering that ET1 and AngII activate NADPH oxidase (Li et al., 2003b; Laplante et al., 2005; Loomis et al., 2005; Pollock, 2005), we used DHE fluoromicrography to determine whether these peptides are responsible for the increase in ROS underlying the cerebrovascular alterations. AngII increases ROS production in the somatosensory cortex (Fig. 7), as previously described (Capone et al., 2011). Topical application of the ROS scavenger MnTBAP blocked the ROS increase, attesting to the specificity of the ROS signal (Fig. 7). Consistent with the cerebrovascular findings, BQ123 or losartan attenuated ROS production only partially (Fig. 7). However, coadministration of BQ123 and losartan blocked ROS production completely (Fig. 7), suggesting that both AngII and ET1 contribute to the increase in ROS mediating the vascular dysfunction. 
A

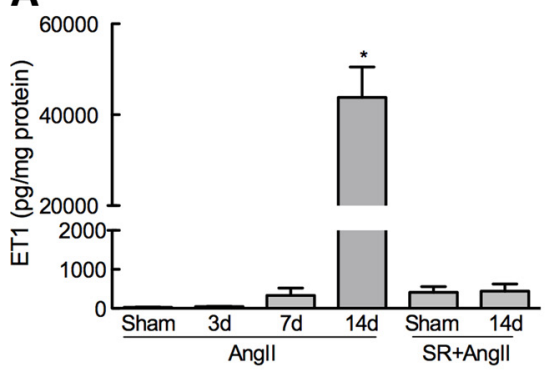

C
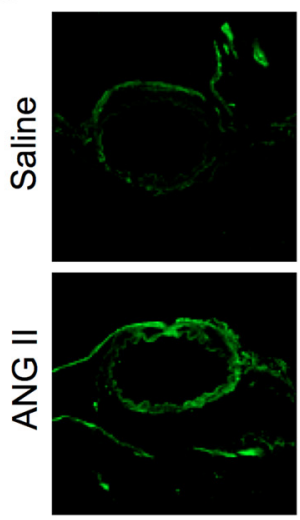

D

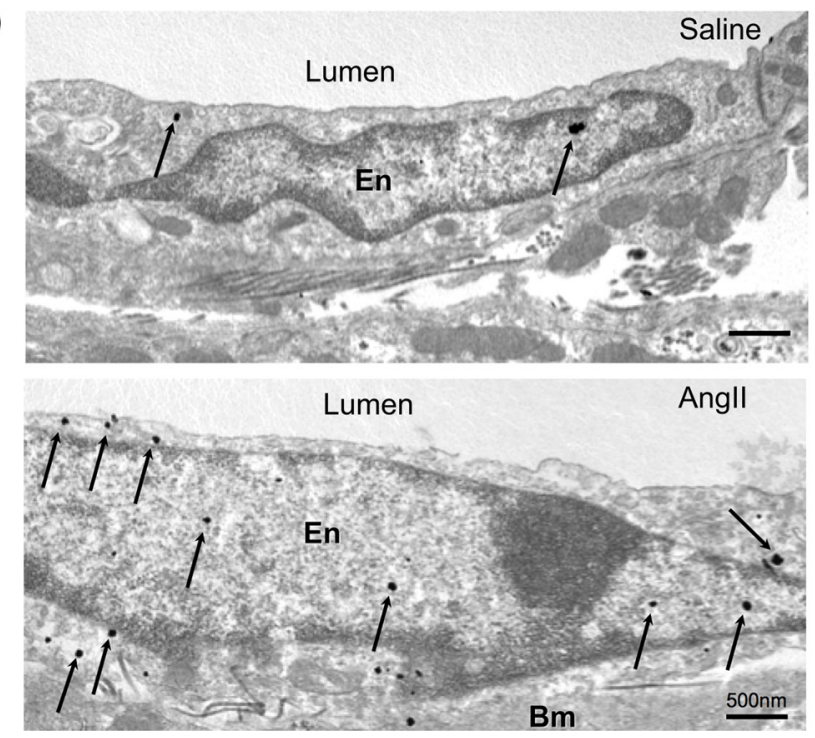

Figure 5. A, Angll infusion increased ET1 in pial cerebrovascular preparations at $14 \mathrm{~d}$. SR49059 (in drinking water, days 7-14) prevents the elevation in ET1 ( ${ }^{*} p<0.05$ form sham; $n=5-6$ per group). $\boldsymbol{B}$, Angll infusion increases ECE-1 mRNA in pial microvascular preparations at $14 \mathrm{~d}\left({ }^{*} p<0.05\right.$ from Saline and $7 \mathrm{~d} ; n=5$ per group). C, ET1 immunoreactivity is increased by Angll infusion in pial arterioles of the somatosensory cortex at $14 \mathrm{~d}$. The endothelial marker CD31 was used to identify the vessels. $\boldsymbol{D}_{\boldsymbol{i}}$ Immunogold electron microscopy demonstrates ET1 in endothelial cells (arrows). Angll infusion (14 d) increases the immunogold particles $(\boldsymbol{D})$.

\section{Discussion}

Summary of the major findings of the study

We have demonstrated that the cerebrovascular alterations induced by administration of slow-pressor doses of AngII, a model that reproduces selected features of human hypertension (Reckelhoff, 2001), depends on ROS production in the SFO. The dysfunction has two components: one is related to release of AVP into the circulation from the PVN and upregulation of ET1 in cerebral blood vessels, and the other depends on activation of AT1 receptors by AngII. ET1 and AngII induce cerebrovascular dysfunction through a common pathway leading to production of ROS and vascular oxidative stress. These findings reveal the participation of central neurohumoral mechanisms involving the SFO in the alterations in neurovascular coupling and endothelium-dependent responses evoked by slow-pressor AngII hypertension. Furthermore, they suggest a novel role of AVP and ET 1 in the cerebrovascular dysfunction.

ROS in the SFO participate both in the cardiovascular and cerebrovascular effects of AngII

The SFO participates in the increase in AP induced by chronic administration of AngII, an effect mediated by ROS (Zimmerman et al., 2004). Circulating AngII does not penetrate the $\mathrm{BBB}$, but the ventromedial core region of the SFO is devoid of BBB (McKinley et al., 2003). Therefore, circulating AngII gains access to the SFO and activates local neurons (Ferguson and Renaud, 1986; McKinley et al., 1992; McKinley et al., 2003). Evidence indicates that AngII in the SFO activates AT1 receptors triggering ROS production by the enzyme NADPH oxidase (Zimmerman et al., 2004; Peterson et al., 2006). The resulting alteration in neuronal calcium homeostasis (Zimmerman et al., 2005) is thought to lead to activation of efferent projections from the SFO, including the PVN. We have shown here that suppression of ROS in the SFO also prevents the alterations in functional hyperemia and endothelium-dependent responses induced by slow-pressor AngII. The attenuation of the dysfunction cannot be explained by the lack of AP increase in mice treated with AdCuZnSOD since we have previously shown that the cerebrovascular effects produced by slow-pressor AngII administration are independent of the associated elevations in AP. Accordingly, the cerebrovascular dysfunction is not observed in phenylephrine hypertension and is present even if doses of AngII that do not increase AP are infused for 2 weeks (Capone et al., 2011). Furthermore, in the present study we observed that the $\mathrm{CBF}$ dysfunction is dampened by V1a, $\mathrm{ET}_{\mathrm{A}}$, or AT1 receptor antagonists despite persistent elevations in AP. Therefore, the suppression of the cerebrovascular dysfunction by AdCuZnSOD gene transfer to the SFO cannot be attributed to the associated effects on AP.

Role of AVP and ET1 in the cerebrovascular dysfunction How can the SFO lead to cerebrovascular dysfunction? The SFO is unlikely to mediate the cerebrovascular responses to AngII through direct neural projections to the somatosensory cortex because the SFO projects predominantly to hypothalamus and 

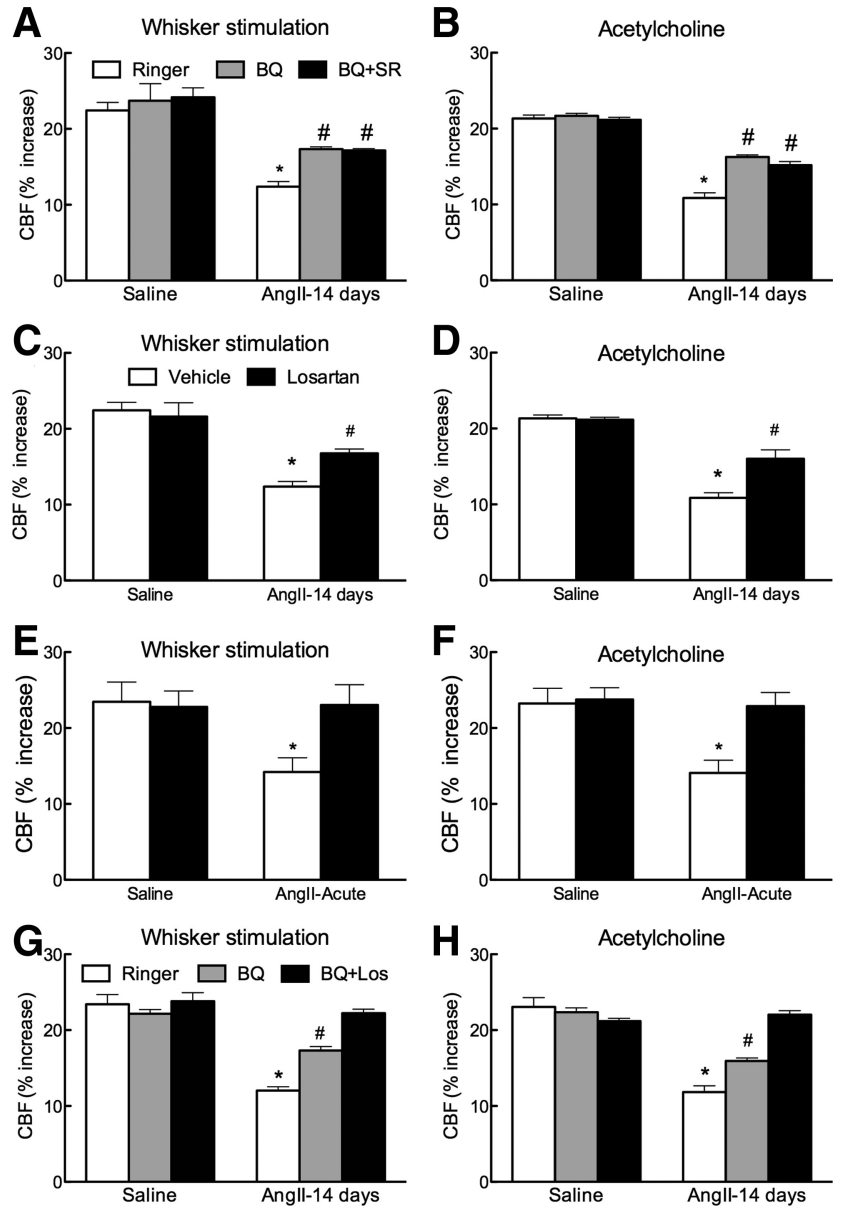

Figure 6. $\quad \boldsymbol{A}, \boldsymbol{B}$, Topical application of the $\mathrm{ET}_{\mathrm{A}}$ receptor antagonist BQ123 $(1 \mu \mathrm{M})$ partially reverses the attenuation of $C B F$ responses to whisker stimulation $(\boldsymbol{A})$ and $A C h(B)$ induced by Angll infusion for $14 \mathrm{~d}$. The effect is not enhanced by pretreatment with SR49059 (in drinking water, days $7-14$ of Angll infusion) ( ${ }^{*} p<0.05$ from respective saline group; ${ }^{\#} p<0.05$ from Ringer's and respective saline groups; $n=5$ per group). $C, D$, Neocortical application of losartan $(5 \mu \mathrm{M})$ partially reverses the attenuation of $\mathrm{CBF}$ responses to whisker stimulation $(\mathrm{C})$ and acetylcholine (D) induced by Angll infusion for $14 \mathrm{~d}\left({ }^{*} p<0.05\right.$ from saline; ${ }^{\#} p<0.05$ from vehicle and saline; $n=5$ per group). $\boldsymbol{E}, \boldsymbol{F}$, Losartan completely reverses the cerebrovascular dysfunction induced by acute Angll administration, attesting to its effectiveness ( ${ }^{*} p<0.05$ from saline; $n=5$ per group). $\mathbf{G}, \boldsymbol{H}$, Topical application of $\mathrm{B} 0123+$ losartan completely reverses the cerebrovascular dysfunction $\left({ }^{*} p<0.05\right.$ from respective saline group; ${ }^{*} p<0.05$ from Ringer's, $\mathrm{BQ}+\mathrm{Los}$ and respective saline groups; $n=5$ per group).

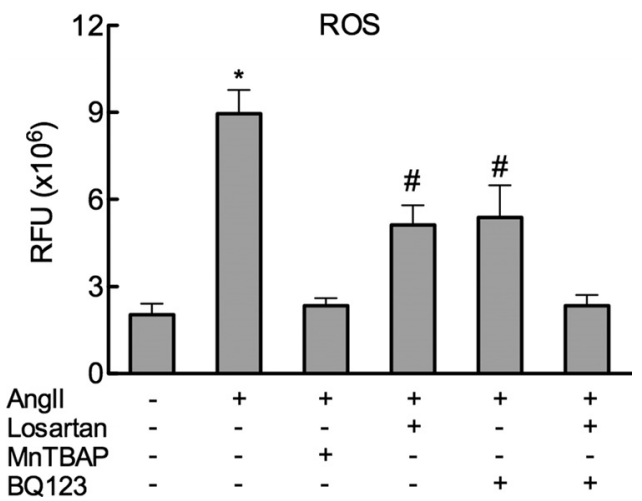

Figure 7. Angll infusion increases ROS in the somatosensory cortex, an effect blocked by neocortical application of MnTBAP $(100 \mu \mathrm{M})$. Losartan and BQ123 attenuate the increase only partially, but they coapplication completely blocks the increase $\left({ }^{*} p<0.05\right.$ from control; ${ }^{\#} p<$ 0.05 from control and Angll alone; $n=5$ per group). RFU, Relative fluorescence units. other autonomic brainstem nuclei (McKinley et al., 2003). Furthermore, we have previously demonstrated that the neurovascular dysfunction induced by slow-pressor AngII is unrelated to effects on cortical neural activity (Capone et al., 2011). Therefore, it is unlikely that the SFO exerts its effect on neurovascular regulation through direct neocortical projections altering neural activity in the somatosensory cortex. On the other hand, the SFO projects to the PVN (McKinley et al., 2003), and is required for the AVP release evoked by intracerebroventricular or systemic injection of AngII (Iovino and Steardo, 1984; Mangiapane et al., 1984). Accordingly, we found that Ang II increases circulating AVP and that inhibition of V1a AVP receptors did not affect resting $\mathrm{CBF}$ or baseline $\mathrm{CBF}$ responses, but it prevented the cerebrovascular dysfunction induced by AngII. These findings demonstrate for the first time an involvement of AVP in the cerebrovascular dysfunction induced by hypertension. AVP, a hormone with powerful cerebrovascular effects (Faraci et al., 1988, 1994), is not directly responsible for the cerebrovascular dysfunction by acting on V1a receptors on cerebral blood vessels, since acute neocortical application a Vla receptor antagonist does not reverse the cerebrovascular dysfunction. Rather, AVP induces ET1 expression in cerebral blood vessels, which in turn, is responsible for the cerebrovascular alterations. This conclusion is supported by the observations that (1) chronic systemic administration of the V1a antagonist blocks the ET1 upregulation in cerebral vessels and ameliorates the dysfunction, and (2) acute neocortical application of the $\mathrm{ET}_{\mathrm{A}}$ antagonist $\mathrm{BQ} 123$ also ameliorates the dysfunction. Our data, together, provide evidence that slow-pressor AngII activates the PVN to release AVP, which, in turn, induces the expression of ET1 in resistance arterioles resulting in cerebrovascular dysfunction.

\section{Role of AngII in the cerebrovascular dysfunction}

However, AVP and ET1 do not account for the totality of the cerebrovascular effects induced by slow-pressor AngII since another component of the dysfunction is related to activation of AT1 receptors by AngII. In our model of AngII hypertension cerebrovascular dysfunction does not occur immediately after the start of the AngII infusion, but it develops after $7 \mathrm{~d}$ (Capone et al., 2011). Thus, the AngII delivered by the osmotic minipumps is not sufficient to induce cerebrovascular dysfunction, at least initially. However, slow-pressor AngII infusion increases endogenous AngII synthesis by the kidney and increases plasma levels of AngII (Gonzalez-Villalobos et al., 2009). Therefore, it is conceivable that higher levels of circulating AngII are produced endogenously during AngII slow-pressor infusion, leading to the observed AT1-dependent cerebrovascular effects. Interestingly, our finding that CuZnSOD gene transfer blocks both the AVP/ ET1 and AngII components of the dysfunction indicates that central pathways represented in the SFO may also be critical for the elevation in endogenous AngII. Another possibility is that the sensitivity of cerebral blood vessels to the effects of AngII increases progressively during the AngII infusion period, but there are no data in support of this hypothesis. Regardless of the mechanisms of the involvement of AngII, central pathways involving ROS signaling in the SFO are upstream of both the AVP/ET1 and AngII components mediating the dysfunction.

\section{ET1 and AngII increase ROS production in cerebral blood vessels}

ET1 and AngII mediate the cerebrovascular dysfunction by increasing ROS production and leading to vascular oxidative stress. We have previously demonstrated that the cerebrovascular dys- 
function induced by slow-pressor AngII is mediated by ROS produced by the enzyme NADPH oxidase (Capone et al., 2011). It is therefore likely that AngII and ET1 activate NADPH oxidase resulting in increased vascular ROS production, a possibility supported by extensive in vivo and in vitro evidence linking these peptides to NADPH oxidase-dependent ROS production (Bedard and Krause, 2007; Faraci, 2011). The mechanisms by which vascular oxidative stress alters the regulation of the cerebral circulation remain to be defined. Our previous data indicate that the dysfunction induced by acute AngII hypertension is mediated by vascular nitrosative stress (Girouard et al., 2007), but it remains to be determined whether a similar mechanism is also involved in slow-pressor AngII hypertension.

\section{Implications for the end organ damage to the brain induced by hypertension}

Hypertension is a major risk factor for stroke and dementia, effects that are related to alterations in the structure and function of the cerebral circulation (Iadecola and Davisson, 2008). Our findings provide new insight into the mechanisms by which hypertension targets cerebral blood vessels. In contrast to the cerebrovascular alterations induced by acute AngII hypertension, which depend entirely on local effect of AngII on cerebral blood vessels (Girouard et al., 2006, 2007), we have shown that slowpressor AngII hypertension exerts its effects through a more intricate pathway involving central ROS signaling and activation of neurohumoral mechanisms leading to AVP release and upregulation of ET1 in cerebral blood vessels. At the same time activation of AT1 receptor by AngII also contributes the dysfunction. While the effects of treatment of hypertension in reducing stroke incidence are well documented (Moskowitz et al., 2010), it is less clear whether antihypertensive treatment reduces the risk of dementia, either vascular cognitive impairment or AD (Knopman, 2009). Clinical trials using antagonist of the renin-angiotensin system have raised the possibility that these agents may have beneficial effects on the brain independent of their ability to lower AP, but other studies have not supported this conclusion (Iadecola and Gorelick, 2004; Kehoe et al., 2009). Our finding that AVP and ET1 are also involved in the cerebrovascular dysfunction raise the possibility that $\mathrm{V} 1 \mathrm{a}$ or $\mathrm{ET}_{\mathrm{A}}$ antagonists, already in clinical use (Barton and Yanagisawa, 2008), in concert with drugs targeting the renin-angiotensin system, may offer a better chance to counteract the devastating cerebrovascular effects of hypertension on the brain.

\section{Conclusions}

We have demonstrated that ROS signaling in central pathways involving the SFO play a critical role in the cerebrovascular dysfunction induced by slow-pressor AngII hypertension. This effect is dependent on neurohumoral effectors leading to increases in circulating AVP, which, in turn, contributes the neurovascular dysfunction by upregulating ET1 in cerebral resistance arterioles. Another component of the response is dependent on activation of AT1 receptors by AngII. Ultimately, ET1 and AngII induce cerebrovascular dysfunction by producing vascular oxidative stress, which, in turn, suppresses functional hyperemia and endothelium-dependent responses. The findings unveil a previously unrecognized central component of the alterations in neurovascular function induced by AngII hypertension and suggest new therapeutic targets to counteract the damaging effects of hypertension on the brain.

\section{References}

Anderson JW, Smith PM, Ferguson AV (2001) Subfornical organ neurons projecting to paraventricular nucleus: whole-cell properties. Brain Res 921:78-85.

Barton M, Yanagisawa M (2008) Endothelin: 20 years from discovery to therapy. Can J Physiol Pharmacol 86:485-498.

Bedard K, Krause KH (2007) The NOX family of ROS-generating NADPH oxidases: physiology and pathophysiology. Physiol Rev 87:245-313.

Capone C, Anrather J, Milner TA, Iadecola C (2009) Estrous cycledependent neurovascular dysfunction induced by angiotensin II in the mouse neocortex. Hypertension 54:302-307.

Capone C, Faraco G, Anrather J, Zhou P, Iadecola C (2010) Cyclooxygenase 1-derived prostaglandin E2 and EP1 receptors are required for the cerebrovascular dysfunction induced by angiotensin II. Hypertension 55:911-917.

Capone C, Faraco G, Park L, Cao X, Davisson RL, Iadecola C (2011) The cerebrovascular dysfunction induced by slow pressor doses of angiotensin II precedes the development of hypertension. Am J Physiol 300:H397-H407.

Cardillo C, Campia U, Kilcoyne CM, Bryant MB, Panza JA (2002) Improved endothelium-dependent vasodilation after blockade of endothelin receptors in patients with essential hypertension. Circulation 105:452-456.

Chan J, Aoki C, Pickel VM (1990) Optimization of differential immunogoldsilver and peroxidase labeling with maintenance of ultrastructure in brain sections before plastic embedding. J Neurosci Methods 33:113-127.

Cipolla MJ (2007) Cerebrovascular function in pregnancy and eclampsia. Hypertension 50:14-24.

Dickinson CJ, Lawrence JR (1963) A slowly developing pressor response to small concentrations of angiotensin. Its bearing on the pathogenesis of chronic renal hypertension. Lancet 1:1354-1356.

Englund E, Brun A, Alling C (1988) White matter changes in dementia of Alzheimer's type. Biochemical and neuropathological correlates. Brain 111:1425-1439.

Faraci FM (2011) Protecting against vascular disease in brain. Am J Physiol Heart Circ Physiol 300:H1566-H1582.

Faraci FM, Mayhan WG, Schmid PG, Heistad DD (1988) Effects of arginine vasopressin on cerebral microvascular pressure. Am J Physiol 255:H70-H76.

Faraci FM, Kinzenbaw D, Heistad DD (1994) Effect of endogenous vasopressin on blood flow to choroid plexus during hypoxia and intracranial hypertension. Am J Physiol 266:H393-H398.

Ferguson AV, Kasting NW (1986) Electrical stimulation in subfornical organ increases plasma vasopressin concentrations in the conscious rat. Am J Physiol 251:R425-R428.

Ferguson AV, Renaud LP (1986) Systemic angiotensin acts at subfornical organ to facilitate activity of neurohypophysial neurons. Am J Physiol 251:R712-R717.

Fernández N, Martínez MA, García-Villalón AL, Monge L, Diéguez G (2001) Cerebral vasoconstriction produced by vasopressin in conscious goats: role of vasopressin $\mathrm{V}(1)$ and $\mathrm{V}(2)$ receptors and nitric oxide. Br J Pharmacol 132:1837-1844.

Fernando MS, Simpson JE, Matthews F, Brayne C, Lewis CE, Barber R, Kalaria RN, Forster G, Esteves F, Wharton SB, Shaw PJ, O’Brien JT, Ince PG (2006) White matter lesions in an unselected cohort of the elderly: molecular pathology suggests origin from chronic hypoperfusion injury. Stroke 37:1391-1398.

Girouard H, Park L, Anrather J, Zhou P, Iadecola C (2006) Angiotensin II attenuates endothelium-dependent responses in the cerebral microcirculation through nox-2-derived radicals. Arterioscler Thromb Vasc Biol 26:826-832.

Girouard H, Park L, Anrather J, Zhou P, Iadecola C (2007) Cerebrovascular nitrosative stress mediates neurovascular and endothelial dysfunction induced by angiotensin II. Arterioscler Thromb Vasc Biol 27:303-309.

Gonzalez-Villalobos RA, Satou R, Seth DM, Semprun-Prieto LC, Katsurada A, Kobori H, Navar LG (2009) Angiotensin-converting enzyme-derived angiotensin II formation during angiotensin II-induced hypertension. Hypertension 53:351-355.

Harrison DG, Gongora MC (2009) Oxidative stress and hypertension. Med Clin N Am 93:621-635.

Iadecola C (1997) Principles and methods for measurement of cerebral blood flow: experimental methods. In: Primer on cerebrovascular diseases (Welsh KMA, Caplan LR, Reis DJ, Siësjo BK, Weir B, eds), pp 34-37. San Diego: Academic. 
Iadecola C (2010) The overlap between neurodegenerative and vascular factors in the pathogenesis of dementia. Acta Neuropathol 120:287-296.

Iadecola C, Davisson RL (2008) Hypertension and cerebrovascular dysfunction. Cell Metab 7:476-484.

Iadecola C, Gorelick PB (2004) Hypertension, angiotensin, and stroke: beyond blood pressure. Stroke 35:348-350.

Iadecola C, Zhang F, Niwa K, Eckman C, Turner SK, Fischer E, Younkin S, Borchelt DR, Hsiao KK, Carlson GA (1999) SOD1 rescues cerebral endothelial dysfunction in mice overexpressing amyloid precursor protein. Nat Neurosci 2:157-161.

Iovino M, Steardo L (1984) Vasopressin release to central and peripheral angiotensin II in rats with lesions of the subfornical organ. Brain Res 322:365-368.

Jennings JR, Muldoon MF, Ryan C, Price JC, Greer P, Sutton-Tyrrell K, van der Veen FM, Meltzer CC (2005) Reduced cerebral blood flow response and compensation among patients with untreated hypertension. Neurology 64:1358-1365.

Kawada N, Imai E, Karber A, Welch WJ, Wilcox CS (2002) A mouse model of angiotensin II slow pressor response: role of oxidative stress. J Am Soc Nephrol 13:2860-2868.

Kazama K, Wang G, Frys K, Anrather J, Iadecola C (2003) Angiotensin II attenuates functional hyperemia in the mouse somatosensory cortex. Am J Physiol 285:H1890-H1899.

Kazama K, Anrather J, Zhou P, Girouard H, Frys K, Milner TA, Iadecola C (2004) Angiotensin II impairs neurovascular coupling in neocortex through NADPH-oxidase-derived radicals. Circ Res 95:1019-1026.

Kehoe PG, Miners S, Love S (2009) Angiotensins in Alzheimer's diseasefriend or foe? Trends Neurosci 32:619-628.

Knopman DS (2009) Hypertension and late-life dementia: a real link? Neurology 72:1716-1717.

Kunz A, Abe T, Hochrainer K, Shimamura M, Anrather J, Racchumi G, Zhou P, Iadecola C (2008) Nuclear factor-\{kappa\}B activation and postischemic inflammation are suppressed in CD36-null mice after middle cerebral artery occlusion. J Neurosci 28:1649-1658.

Laplante MA, Wu R, Moreau P, de Champlain J (2005) Endothelin mediates superoxide production in angiotensin II-induced hypertension in rats. Free Radic Biol Med 38:589-596.

Li L, Galligan JJ, Fink GD, Chen AF (2003a) Vasopressin induces vascular superoxide via endothelin-1 in mineralocorticoid hypertension. Hypertension 41:663-668.

Li L, Fink GD, Watts SW, Northcott CA, Galligan JJ, Pagano PJ, Chen AF (2003b) Endothelin-1 increases vascular superoxide via endothelin(A)$\mathrm{NADPH}$ oxidase pathway in low-renin hypertension. Circulation 107:1053-1058

Lindley TE, Doobay MF, Sharma RV, Davisson RL (2004) Superoxide is involved in the central nervous system activation and sympathoexcitation of myocardial infarction-induced heart failure. Circ Res 94:402-409.

Loomis ED, Sullivan JC, Osmond DA, Pollock DM, Pollock JS (2005) Endothelin mediates superoxide production and vasoconstriction through activation of NADPH oxidase and uncoupled nitric-oxide synthase in the rat aorta. J Pharmacol Exp Ther 315:1058-1064.

Mangiapane ML, Thrasher TN, Keil LC, Simpson JB, Ganong WF (1984) Role for the subfornical organ in vasopressin release. Brain Res Bull 13:43-47.

Markus HS, Lythgoe DJ, Ostegaard L, O’Sullivan M, Williams SC (2000) Reduced cerebral blood flow in white matter in ischaemic leukoaraiosis demonstrated using quantitative exogenous contrast based perfusion MRI. J Neurol Neurosurg Psychiatry 69:48-53.

Matsushita K, Kuriyama Y, Nagatsuka K, Nakamura M, Sawada T, Omae T (1994) Periventricular white matter lucency and cerebral blood flow autoregulation in hypertensive patients. Hypertension 23:565-568.

McKinley MJ, Badoer E, Oldfield BJ (1992) Intravenous angiotensin II induces Fos-immunoreactivity in circumventricular organs of the lamina terminalis. Brain Res 594:295-300.

McKinley MJ, McAllen RM, Davern P, Giles ME, Penschow J, Sunn N, Uscha- kov A, Oldfield BJ (2003) The sensory circumventricular organs of the mammalian brain. Adv Anat Embryol Cell Biol 172:III-XII, 1-122.

Milner TA, Thompson LI, Wang G, Kievits JA, Martin E, Zhou P, McEwen BS, Pfaff DW, Waters EM (2010) Distribution of estrogen receptor $\beta$ containing cells in the brains of bacterial artificial chromosome transgenic mice. Brain Res 1351:74-96.

Moskowitz MA, Lo EH, Iadecola C (2010) The science of stroke: mechanisms in search of treatments. Neuron 67:181-198.

Niwa K, Haensel C, Ross ME, Iadecola C (2001) Cyclooxygenase-1 participates in selected vasodilator responses of the cerebral circulation. Circ Res 88:600-608.

Osborn JW, Fink GD, Sved AF, Toney GM, Raizada MK (2007) Circulating angiotensin II and dietary salt: converging signals for neurogenic hypertension. Curr Hypertens Rep 9:228-235.

Park L, Gallo EF, Anrather J, Wang G, Norris EH, Paul J, Strickland S, Iadecola C (2008) Key role of tissue plasminogen activator in neurovascular coupling. Proc Natl Acad Sci U S A 105:1073-1078.

Park L, Wang G, Zhou P, Zhou J, Pitstick R, Previti ML, Younkin L, Younkin SG, Van Nostrand WE, Cho S, Anrather J, Carlson GA, Iadecola C (2011) Scavenger receptor CD36 is essential for the cerebrovascular oxidative stress and neurovascular dysfunction induced by amyloid-beta. Proc Natl Acad Sci U S A 108:5063-5068.

Peterson JR, Sharma RV, Davisson RL (2006) Reactive oxygen species in the neuropathogenesis of hypertension. Curr Hypertens Rep 8:232-241.

Peterson JR, Burmeister MA, Tian X, Zhou Y, Guruju MR, Stupinski JA, Sharma RV, Davisson RL (2009) Genetic silencing of Nox2 and Nox4 reveals differential roles of these NADPH oxidase homologues in the vasopressor and dipsogenic effects of brain angiotensin II. Hypertension 54:1106-1114.

Phillis JW (1989) Adenosine in the control of the cerebral circulation. Cerebrovasc Brain Metab Rev 1:26-54.

Pollock DM (2005) Endothelin, angiotensin, and oxidative stress in hypertension. Hypertension 45:477-480.

Reckelhoff JF (2001) Gender differences in the regulation of blood pressure. Hypertension 37:1199-1208.

Tharaux PL, Chatziantoniou C, Casellas D, Fouassier L, Ardaillou R, Dussaule JC (1999) Vascular endothelin-1 gene expression and synthesis and effect on renal type I collagen synthesis and nephroangiosclerosis during nitric oxide synthase inhibition in rats. Circulation 99:2185-2191.

Thibonnier M, Coles P, Thibonnier A, Shoham M (2002) Molecular pharmacology and modeling of vasopressin receptors. Prog Brain Res 139:179-196.

Unverzagt FW, McClure LA, Wadley VG, Jenny NS, Go RC, Cushman M, Kissela BM, Kelley BJ, Kennedy R, Moy CS, Howard V, Howard G (2011) Vascular risk factors and cognitive impairment in a stroke-free cohort. Neurology 77:1729-1736.

van Dijk EJ, Breteler MM, Schmidt R, Berger K, Nilsson LG, Oudkerk M, Pajak A, Sans S, de Ridder M, Dufouil C, Fuhrer R, Giampaoli S, Launer LJ, Hofman A (2004) The association between blood pressure, hypertension, and cerebral white matter lesions: cardiovascular determinants of dementia study. Hypertension 44:625-630.

Vermeer SE, Hollander M, van Dijk EJ, Hofman A, Koudstaal PJ, Breteler MM (2003) Silent brain infarcts and white matter lesions increase stroke risk in the general population: the Rotterdam Scan Study. Stroke 34:1126-1129.

Yamada M, Lamping KG, Duttaroy A, Zhang W, Cui Y, Bymaster FP, McKinzie DL, Felder CC, Deng CX, Faraci FM, Wess J (2001) Cholinergic dilation of cerebral blood vessels is abolished in $\mathrm{M}(5)$ muscarinic acetylcholine receptor knockout mice. Proc Natl Acad Sci U S A 98:14096-14101.

Zimmerman MC, Lazartigues E, Sharma RV, Davisson RL (2004) Hypertension caused by angiotensin II infusion involves increased superoxide production in the central nervous system. Circ Res 95:210-216.

Zimmerman MC, Sharma RV, Davisson RL (2005) Superoxide mediates angiotensin II-induced influx of extracellular calcium in neural cells. Hypertension 45:717-723. 